\title{
Effects of association, frequency, and stimulus quality on naming words in the presence or absence of pseudowords
}

\author{
CLAUDIA CARELLO, GEORGIJE LUKATELA, MIRA PETER, and M. T. TURVEY \\ University of Connecticut, Storrs, Connecticut \\ and Haskins Laboratories, New Haven, Connecticut
}

\begin{abstract}
According to classical dual-route theory, effects of associative priming and frequency on the naming of printed words arise from lexical access and should be weak or absent when word names are assembled prelexically. Assembled naming would be more likely in a shallow orthography, especially in the presence of nonwords. This hypothesis was examined with the shallow Serbo-Croatian orthography. Interactions between association, frequency, and stimulus quality were also examined in both Serbo-Croatian and English. Contrary to classical dual-route theory, both lexical effects were found for naming words in Serbo-Croatian, with or without nonwords. Neither interaction was significant in Serbo-Croatian and only association $\times$ quality was significant in English. Discussion focused on (a) the claim that lexical effects on naming in a shallow orthography constitute prima facie evidence against either prelexical phonology or the orthographic depth hypothesis, and (b) the possible factorization of frequency and active associative knowledge in naming words.
\end{abstract}

The rapid naming task places few explicit demands on the reader. It does not, in principle, require that the reader know the meaning of the letter string or what words it is related to or how common it is or even if it is, in fact, a word. Nonetheless, the latency to initiate the pronunciation of a letter string can be affected by all of these factors. When a target is preceded by an associative context, it is named faster than when it is preceded by an unrelated context (e.g., Meyer, Schvaneveldt, \& Ruddy, 1975; Seidenberg, Waters, Sanders, \& Langer, 1984). High-frequency words tend to be named faster than lowfrequency words (e.g., Forster \& Chambers, 1973; McCann, Besner, \& Davelaar, 1988), and words tend to be named faster than nonwords (e.g., Forster \& Chambers, 1973; Frederiksen \& Kroll, 1976). Association, frequency, and lexicality are understood to exert their influences only after the lexicon has been accessed. Granting this understanding, what do such effects suggest about how rapid naming is accomplished?

Discussions of naming often are framed in terms of accessed versus assembled phonology. In the former, visual characteristics of the letter string are mapped in whole word fashion onto lexical representations where information about phonology is accessed. In the latter, the visual form of the letter string is recoded into corresponding phonological constituents, and this assembled

This research was supported in part by National Institute of Child Health and Human Development Grants HD-08495 and HD-01994 to the University of Belgrade and Haskins Laboratories, respectively. Communications concerning the manuscript should be sent to C. Carello, Haskins Laboratories, 270 Crown Street, New Haven, CT 06511 (e-mail: cespal@uconnvm). phonological representation is the basis of lexical access itself. A number of recent papers have highlighted the understanding from classical dual-route theory (Coltheart, 1978) that lexical effects on naming arise from visual access of the lexicon and that consequently the presence of such effects can be taken as evidence against phonologically mediated access (e.g., Baluch \& Besner, 1991; Sebastián-Gallés, 1991; Tabossi \& Laghi, 1992). The substance of the argument is that the assembling of a name on the basis of a prelexical phonological code should not reflect influences that arise after assembly, that is, within the lexicon. A corollary of this argument is that if assembled phonology is dominant in shallow orthographies-those with highly regular spelling to sound correspondences - then naming in such orthographies should not be sensitive to lexical influences. Sebastián-Gallés (1991) found lexical influences on naming in the shallow Spanish orthography and concluded that the lexicon is ordinarily accessed visually regardless of the regularity of the spelling-to-sound relationship. Her argument that phonological mediation of word recognition in shallow orthographies is limited to situations that hinder reliance on visual access is complemented by the observation that lexical effects on naming Italian words are enhanced by experimental conditions that discourage phonological mediation (Tabossi \& Laghi, 1992). It is argued that phonological mediation is encouraged when pseudowords have to be named along with words: Because pseudowords have no lexical representation to be accessed, naming them must be phonologically mediated and the word recognition system must keep both processing routes open (Baluch \& Besner, 1991; Sebastián-Gallés, 1991; Tabossi \& Laghi, 
1992). Without pseudowords, the dominant reliance on visual access that putatively typifies ordinary word recognition is manifest, as evidenced by the significance of semantic and associative priming and the frequency of the target words (see Besner \& Smith, 1992b, for a review).

Contrary to the expectations from classical dual-route theory, and contrary to research on the shallow orthography of Italian, experiments with the shallow SerboCroatian orthography have found large associative priming effects (ranging from 13 to $40 \mathrm{msec}$ ) on naming words in experiments in which subjects were additionally required to name pseudowords (Carello, Lukatela, \& Turvey, 1988, Experiments 1 and 3; Lukatela, Feldman, Turvey, Carello, \& Katz, 1989, Experiment 6; Lukatela, Turvey, Feldman, Carello, \& Katz, 1989, Experiment 5). ${ }^{1}$ Similarly, significant frequency effects in the naming of Serbo-Croatian words have been found in experiments in which pseudowords were named along with words (Frost, Katz, \& Bentin, 1987; Lukatela \& Turvey, $1990 \mathrm{~b}$, Experiment 7$).^{2}$ Within the body of literature on Serbo-Croatian, these lexical effects on naming have been understood as automatic consequences of a prelexical computation of phonological codes tuned by an automatic lexically based "clean up" (Lukatela, Carello, \& Turvey, 1990; Lukatela \& Turvey, 1990a, 1990b; Lukatela, Turvey, et al., 1989; Lukatela, Turvey, \& Todorović, 1991). Via a hypothesized connective matrix relating orthographic to phonological subsymbols, any given Serbo-Croatian word activates as many distinct phonological patterns as its orthographic structure permits. For most Serbo-Croatian words, only one phonological pattern will attain significant activation levels given the precision of the mapping from orthography. For some Serbo-Croatian words, those that are written with letters shared by the Roman and Cyrillic transcriptions, more than one phonological pattern will be activated to the extent that the shared letters involved specify different phonemes in the two transcriptions. Take BETAP as an example. Read strictly through the letter-tosound correspondences of the Cyrillic alphabet, this letter string is pronounced /vetar/ and is a high-frequency noun meaning "wind." Read strictly through the letterto-sound correspondences of the Roman alphabet, BETAP is pronounced /betap/, a nonword. Reading with a mixture of the two sets of correspondences, Cyrillic and Roman, leads to the pronunciations /vetap/ and /betar/, which are also nonwords. The word meaning "wind" is transcribed in the Roman alphabet as VETAR. This letter string supports only a single reading, /vetar/. No other readings are possible. VETAR, unlike its Cyrillic mate BETAP, is phonologically unambiguous. In naming by proficient bialphabetic readers, the latencies for BETAP, and for letter strings like it, are considerably longer than the latencies for VETAR, and for letter strings like it, even though the two letter strings are equal in frequency, syllabic structure, number of letters, and meaning (see Carello, Turvey, \& Lukatela, 1992, and Lukatela \& Turvey, 1990b, 1991, for reviews of this phonological am- biguity effect). The resolution of a (unique) phonological code to support correct naming takes longer for BETAP than for VETAR (Lukatela, Turvey, et al., 1989). Under ordinary circumstances, resolving the name of a SerboCroatian word must rely on more than the orthographicphonological network. The phonological-lexical network, via which phonological patterns activate lexical patterns, must also contribute significantly. By reference to lexical knowledge, a unique pronunciation of a phonologically ambiguous Serbo-Croatian word can be achieved, and only by reference to lexical knowledge can the stress pattern of any Serbo-Croatian word, ambiguous or unique, be assigned (Carello et al., 1988, 1994; Lukatela, Feldman, et al., 1989; Lukatela \& Turvey, 1990a, 1990b).

In sum, the associative priming and frequency effects observed in Serbo-Croatian are addressed via a singleroute account of naming in which all letter strings are processed by (a) a lower orthographic-phonological network that generates automatically all phonological patterns specified by a letter string, and (b) a higher phonological-lexical network, shaped by individual word frequencies, that enhances phonological pattern selection through adaptive resonance (Grossberg \& Stone, 1986).

The research on associative priming is consistent with the foregoing in that associative priming is greater for phonologically ambiguous words than for phonologically unique words (Lukatela, Feldman, et al., 1989, Experiment 6,33 vs. $13 \mathrm{msec}$ ). By the above model, preactivation of the target word's lexical representation aids pattern selection at the lower phonological level more for BETAP (which cannot resolve a unique pronunciation without lexical influence) than for VETAR (which can).

The contrasts between ambiguous and unique SerboCroatian words in naming speed (ambiguous were $40 \mathrm{msec}$ slower in Experiment 4 and $22 \mathrm{msec}$ slower in Experiment 6) and sensitivity to associative priming observed in the experiments of Lukatela, Feldman, et al. (1989) are illuminating, because they anticipate the contrasts between opaque and transparent Persian words in naming speed and sensitivity to associative priming observed by Baluch and Besner (1991). In opaque Persian words, in contrast to transparent Persian words, vowels are not represented explicitly (although diacritics are used with beginning readers). Said differently, opaque words are phonologically ambiguous and transparent words are (more nearly) phonologically unique. Baluch and Besner (1991, Experiment 1) found that opaque words were named $59 \mathrm{msec}$ more slowly than transparent words and that, in the presence of pseudowords, the associative priming effect for opaque words was $21 \mathrm{msec}$ whereas the associative priming effect for transparent words was $2 \mathrm{msec}$. In short, their results replicated the main effect and interaction observed by Lukatela, Feldman, et al. (1989) with the functionally similar phonologically ambiguous and unique words of Serbo-Croatian. Similar results have recently been reported for Hebrew: phonologically ambiguous unpointed words took longer 
to name than phonologically unambiguous pointed words, and the semantic priming effect was larger for the unpointed than for the pointed (Frost, 1994).

To account for the different associative priming effects, Baluch and Besner hypothesized that opaque words used the visual or lexical route and that transparent words used the phonological or nonlexical route. To interpret the data in a manner consistent with this hypothesis, however, they had to allow an interpretation of the naming difference between the two word kinds that was novel within the context of classical dual-process theory and contrary to a major precept, namely, that the phonologically mediated route was faster than the visual, lexical route. Moreover, transparent nonwords were named $41 \mathrm{msec}$ faster than opaque words. Given the benefits that are supposed to accrue to familiar letter strings at output, this large difference favoring nonwords must mean an even greater speed advantage for assembled than for addressed phonology, contrary to classical dual-route theory.

Other features of the Baluch and Besner (1991) data would seem to pose a major problem for the interpretation from classical dual-route theory. In their Experiment 2 , transparent pseudowords were omitted in an attempt to encourage use of the lexical route. Indeed, effects of association and frequency were found for both opaque and transparent words. The latter were faster than the former, however, requiring an additional adjustment to classical dual-process theory, namely, that despite being equivalent in frequency of occurrence, visual word patterns without vowels were linked less strongly to their lexical representations than were visual word patterns with vowels. In their Experiment $3 a$, when subjects named only transparent Persian words, high-frequency (HF) words were named faster than low-frequency (LF) words, implying that access by the lexical route had preceded that by the nonlexical route. Transparent Persian words mixed with transparent nonwords (Experiment $3 b$ ), however, failed to reveal a frequency effect. By the classical tenets of dual-route theory, the lexical route should be operating along with the nonlexical route, and the lexical route should be faster (as their Experiment 3a ostensibly confirmed). Accordingly, a frequency effect must always be seen. For there to be no frequency effect with the inclusion of nonwords means that the lexical route can be made inoperative or ignored. In their model, the switch is turned by the decision that a letter string contains a vowel. ${ }^{3}$ But to propose an optional status for visual access is to abandon a major cornerstone of dualroute theory (a drastic move that some contemporary dual-process theorists are willing to make, e.g., Paap, Noel, \& Johansen, 1992).

Accepting the possibility that the lexical route is optional leads to its own conundrum: If the lexical routine is abandoned for transparent words in the presence of pseudowords, then it is not clear-within dual-process theory-why such words should be named significantly faster than pseudowords. The word-pseudoword difference is customarily taken to reflect reliance on a lexical route for words. This anomaly is not limited to a shallow orthography - a similar persistence of the word-nonword difference without a frequency effect on naming has been reported for English (Scarborough, Cortese, \& Scarborough, 1977, Experiment 3). To address this difficulty, Baluch and Besner suggest (following McCann \& Besner, 1987) an additional phonology-sensitive but frequency-insensitive lexicon after the normal lexicon has been accessed (but see Lukatela \& Turvey, 1993, and Taft \& Russell, 1992, for challenges to this account).

Clearly, no self-consistent account of the naming of opaque and transparent Persian words can be given within classical dual-route theory and the preservation of any account in terms of two independent routes requires significant ad hoc embellishments and adjustments. ${ }^{4}$ To the contrary, the relevant data seem to be more in keeping with the single-route, phonologically based model developed for Serbo-Croatian. That model would predict a slower naming of opaque Persian words given the greater number of candidate phonological patterns that must be generated by the connective matrix relating orthographic substructure to phonological substructure. In Serbo-Croatian, a word is responded to more slowly the more ambiguous letters it contains (e.g., Feldman \& Turvey, 1983). Similarly, in unpointed Hebrew (which is functionally like opaque Persian), the greater the number of vowels unspecified in a word and, therefore, the greater the number of computed phonological patterns, the more slowly is the word named (Frost, in press). Customarily, unpointed Hebrew is interpreted within classical dual-route theory as being processed by the visual or lexical route. The preceding observation contradicts this conventional interpretation. At this juncture, it seems more plausible to hypothesize that, whatever the orthography, word names are assembled prelexically, with a subsequent lexicon-based "clean up" process that enhances the assembled phonological patterns so that a unique pattern (a unique name) is selected regardless of the number of active competing phonological patterns. By this hypothesis, observed effects of frequency and associative priming cannot be taken as indicators of nonassembled phonology, and reductions in these effects (in the presence of nonwords) cannot be taken as indicators of assembled phonology.

A particularly compelling expression of the difficulties facing the logic of classical dual-route theorists is the fact that both orthographically deep English (Frost et al., 1987; Tabossi \& Laghi, 1992) and orthographically shallow Serbo-Croatian reveal associative priming of naming in the presence of pseudowords. Where naming English words in the presence of pseudowords and in the absence of pseudowords have been compared directly, no difference in degree of priming has been observed (Keefe \& Neely, 1990). If the average English reader can use both routes, and if the presence of nonwords biases the reader to the nonlexical route, as argued (Baluch \& Besner, 1991; Tabossi \& Laghi, 1992), then a difference in priming magnitude should be realized favoring the condition in which only words are named. 
Similarly, if English pseudowords bias the fluent English reader to assembled phonology, then experiments in which very many stimuli are pseudohomophones should reveal reduced lexical effects. Contradicting this assumption is the phenomenon of pseudohomophone associative priming of naming (HOAP-DESPAIR), which occurs pronouncedly in the presence of a high proportion of pseudohomophones that must be read silently by the subject (Lukatela \& Turvey, 1991, 1993). The form of the difficulty posed by Serbo-Croatian is that a wide variety of experimental paradigms have produced results that resist any consistent interpretation in terms of visual access, but which are readily and consistently accommodated by the hypotheses that phonology is assembled and lexical access is only by phonology (see Carello et al., 1992, and Lukatela \& Turvey, 1990b, 1991, for reviews). The argument from classical dual-route theorythat Serbo-Croatian readers are using a lexical route in experiments that show effects of associative priming and word frequency-is anomalous, therefore, given the weight of the experimental evidence.

Our primary purpose in the present article is to reexamine the status of associative priming and frequency effects on naming Serbo-Croatian words within experimental settings that include and exclude pseudowords. Tests of a word-frequency influence have been conducted only twice, and both times were subsidiary to other kinds of evaluations - of phonemic priming in Lukatela and Turvey (1990b) and of orthographic differences in Frost et al. (1987). Tests of the influence of associative primes in the presence of pseudowords have been conducted a number of times (as noted), but the positive outcomes have been questioned on grounds of subtle and inadvertent stimulus manipulations that could have overridden the pseudoword influence (Tabossi \& Laghi, 1992).

\section{EXPERIMENT 1}

Experiment 1 examined the associative priming of naming in Serbo-Croatian under the following conditions: (a) all stimuli were phonologically unambiguous, (b) one half of the stimuli were pseudowords, none of which were preceded by associates of their source words, (c) all word stimuli were stressed regularly, (d) the word stimuli were evenly divided into sets of high and low familiarity, and (e) target stimuli were presented either intact or degraded by overlapping visual noise.

Behind Condition a is the hypothesis that resolving a unique pronunciation for a phonologically ambiguous word demands a lexical contribution. Accordingly, given the flexibility allowed by classical dual-route theory, restricting the stimuli to phonologically unambiguous forms (e.g., VETAR) should bias processing in favor of the assembled or nonlexical route. The latter expectation would be in accord with Baluch and Besner's (1991) prediction (unsupported by their Experiment 3a) for the transparent Persian words that are functionally similar to unique Serbo-Croatian words.
Behind Condition $b$ is the major hypothesis that the presence of pseudowords discourages a reliance on the lexical route. Also behind Condition $b$ is a misunderstanding by Tabossi and Laghi (1992) of the nature of the pseudowords used in previous investigations of associative priming in Serbo-Croatian. Tabossi and Laghi recognized the demonstrations of associative priming in the presence of pseudowords by Carello et al. (1988) and Lukatela, Feldman, et al. (1989), but dismissed them because of what they deemed to be peculiarities of the pseudowords that would have biased the subjects toward the lexical route and aspects of the data suggestive of such a bias. Tabossi and Laghi reported that the pseudowords in these experiments were derived from the target words, that the source words for these pseudowords were associates of their primes, and that they were, like the words, affected significantly by the primes. It was the case, however, that none of the reported features characterized Lukatela, Feldman, et al.'s Experiment 6 and that the Carello et al. study found a priming of pseudowords when the control primes were asterisks (see their Experiment 1 and their Table 1) but not when the control primes were unrelated words (see their Experiment 3 and their Table 3). To dispel these misunderstandings explicitly, the target pseudowords of Experiment 1 were derived from a set of words independent of the target words; both kinds of targets were preceded by word primes; for target words, the primes were either associates or nonassociates; and for target pseudowords, a prime was never associated with a pseudoword's source word. These restrictions on the pseudoword stimuli should encourage assembled phonology and discourage addressed phonology.

Behind Condition $\mathrm{c}$ is the hypothesis that stress is retrieved from the lexicon. When the stress patterns of experimental stimuli are varied, the use of lexical knowledge is emphasized. Tabossi and Laghi (1992) report that associative priming is absent in Italian when words are named in the presence of pseudowords (their Experiment 3 ) but is present when a good proportion (20\%) of those words are stressed irregularly (their Experiment 4). In accordance with the expectations of Tabossi and Laghi, using only regularly stressed Serbo-Croatian words should further discourage (along with the presence of pseudowords) reliance on the lexical route and encourage reliance on the nonlexical route.

Behind Condition $\mathbf{d}$ is the hypothesis that familiarity with a word exerts its influence via the lexical route. Accordingly, on the theory of two independent routes, if naming is restricted to the nonlexical route, effects of familiarity or frequency should not be seen. Support for this expectation from manipulations within shallow orthographies is equivocal. For example, when nonwords were included in the stimulus set, frequency or familiarity did not affect naming Dutch (Hudson \& Bergman, 1985) and transparent Persian (Baluch \& Besner, 1991) but did affect naming Serbo-Croatian (Frost et al., 1987; Lukatela \& Turvey, 1990b), Spanish (Sebastián-Gallés, 
1991), and Japanese Kana (Besner \& Hildebrandt, 1987). ${ }^{5}$ Support for this expectation is also equivocal within the deeper English orthography. Scarborough et al. (1977) found no frequency effect on naming in the presence of nonwords, whereas Forster and Chambers (1973) found a large (71-msec) effect (see also Frost et al., 1987). Frederiksen and Kroll (1976) found that the significant frequency effect in the absence of nonwords was somewhat diminished when nonwords were included.

Finally, behind Condition e is the empirical observation that associative priming tends to be exaggerated for target stimuli that are degraded (e.g., Meyer et al., 1975), the issue of whether the inclusion of nonassociated primes is sufficient to produce the association $\times$ stimulus quality interaction in Serbo-Croatian, and the need to evaluate the relationship between stimulus quality and word frequency in determining naming (Besner \& Smith, 1992b). Lukatela and Turvey (1987) failed to replicate the interaction often seen in English with Serbo-Croatian materials. Borowsky and Besner (1991) suggested that the failure was due to the absence of a linguistic baseline; Lukatela and Turvey (1987) had used asterisks and associated words as primes rather than nonassociates and associates, respectively. In the present experiment, as noted, all primes (experimental and control) were words. Accordingly, if Borowsky and Besner are correct, an association $X$ stimulus quality interaction should be evident.

Behind an examination of the frequency $\times$ stimulus quality interaction is the novel and theoretically important hypothesis that degradation affects the lexicon that is accessed directly by the visual route but that frequency is coded outside this orthographic lexiconspecifically, within its connections to the semantic memory and the memory for word names (Besner \& Smith, 1992b). Accordingly, frequency should add to degradation's influence on word naming. The regularly observed interactiveness of association and stimulus quality follows from a hypothesized two-way interaction of the lexicon and semantic memory. A primed semantic memory becomes a primed orthographic lexicon, the site of stimulus quality. effects (Besner \& Smith, 1992b). In sum, there is within classical dual-route theory a way of construing the interrelations among the visually accessed lexicon and its attendant memory systems for word meanings and word names that predicts, for word naming, different dependencies of stimulus quality on frequency and context.

Additionally, with respect to Condition e, given the fact that Conditions a-c were intended to weaken the effect of associative primes by reducing dependence on the lexical route, a comparison of degraded and intact target stimuli should provide a means of distinguishing weak associative priming from no associative priming.

In sum, Experiment 1 was designed primarily to test the hypothesis that associative priming and wordfrequency effects on naming in the shallow SerboCroatian orthography should be eliminated by the pres- ence of pseudowords which putatively deflect word processing from the lexical to the nonlexical route (e.g., Baluch \& Besner, 1991; Besner \& Smith, 1992a; Tabossi \& Laghi, 1992). This hypothesis, constructed as it is within classical dual-route theory, does not reflect the expectations from the single, phonological-route interpretation of word recognition. On the latter interpretation, the names of words and pseudowords are ordinarily computed in the same way, and thus no strategic shifts in naming words should follow necessarily from the additional requirement to name pseudowords. Our expectation was that Experiment 1 should confirm the research of Carello et al. (1988), Lukatela, Feldman, et al. (1989), and Lukatela, Turvey, et al. (1989) by revealing associative priming and the research of Frost et al. (1987) and Lukatela and Turvey (1990b) by revealing an effect of word frequency.

\section{Method}

Subjects. Thirty-six high school seniors from the Fifth Belgrade Gymnasium served as subjects. Each subject was assigned to one of four counterbalancing groups, according to when the subject appeared at the laboratory.

Materials. Associated pairs were generated by the population from which the subjects were drawn. A column of 196 isolated test words was printed on response sheets that were distributed among 34 students in a class. For each word, the students were requested to write down the first 5 words that came to mind (that is, to identify the given word's associates). They were urged to respond quickly and to make no corrections. From the completed response sheets, a list of 160 related context-target pairs was created, with all but 3 words conforming to the standard stress pattern (emphasis on the first syllable). The target words from these related pairs were printed on other response sheets that were presented to another class of 28 different students for familiarity evaluation, on a scale from 1 to 5 . The evaluated test words were arranged in descending order of familiarity. The top 40 words were designated the high-familiarity targets and the bottom 40 words were designated the low-familiarity targets. With their previously generated associates, these constituted the related pairs. By an appropriate repairing of contexts and targets, 40 high-familiarity and 40 lowfamiliarity unrelated context pairs were created. The remaining 80 words from the middle of the familiarity ratings were used as source words for pseudoword targets, which were generated from them by changing the initial or middle character. These were paired with words that were unrelated to the source words. On half of the trials (associated and unrelated, high and low frequency, word and pseudoword), a 72-element random-dot pattern was superimposed on the targets.

Design. The major constraint on the design was that a given subject never encountered a given pair more than once. Among the word targets, there were eight $(2 \times 2 \times 2)$ stimulus types (context $x$ stimulus quality $\times$ target frequency), and every subject was presented with 10 word pairs from each of the eight types. In addition, each subject saw a filler set (the same for all subjects) of 16 unrelated word-word pairs for a total of 96 word targets. Sixteen wordpseudoword fillers were also included for a total of 96 pseudoword targets. The experimental sequence was divided into four sublists, with a brief rest after each sublist. Stimulus types were ordered pseudorandomly within each sublist. The experimental sequence was preceded by a practice sequence of 36 stimulus pairs.

Procedure. On each trial, after an auditory warning signal, a letter string (the context) appeared for $500 \mathrm{msec}$ above the fixation point. After an interstimulus interval of $100 \mathrm{msec}$, another letter 
string appeared below the fixation point for $500 \mathrm{msec}$. Subjects were required to pronounce the lower letter string (i.e., the target) as quickly and as distinctly as possible. The subjects were told that silently reading the upper string might make them more accurate in reading aloud the target. To ensure that the subjects were reading the primes, a computer message occasionally (on fewer than $5 \%$ of the trials) requested that they report the prime orally after the target word was named.

\section{Results and Discussion}

Minimum and maximum acceptable latencies were set at \pm 2 standard deviations. Table 1 shows mean wordnaming latencies, mean errors, and standard deviations for the eight types of word-word pairs. A 2 (associative context) $\times 2$ (stimulus quality) $\times 2$ (familiarity) analysis of variance (ANOVA) on word-naming latencies and word-naming errors was conducted with subjects $(F 1)$ and items $(F 2)$ as error terms. The error analyses yielded no significant effects.

Associative priming. Contrary to the hypotheses of Tabossi and Laghi (1992), the ANOVA revealed a significant main effect of associative priming on latency in the presence of pseudowords and in the absence of unpredictable stress patterns [associated $=526 \mathrm{msec}$ vs. unassociated $=537 \mathrm{msec} ; F 1(1,35)=24.52, p<.001$, $F 2(1,78)=9.54, p<.01]$. This outcome is in agreement with that of previous research on Serbo-Croatian by Carello et al. (1988), Lukatela, Feldman, et al. (1989), and Lukatela, Turvey, et al. (1989) and at odds with that of Serbo-Croatian studies by Katz and Feldman (1983) and Frost et al. (1987). With respect to other shallow orthographies, the observed priming in the presence of pseudowords is in agreement with the research of Sebastián-Gallés (1991) on Spanish but contrary to an experiment (Experiment 3 ) by Tabossi and Laghi (1992) on Italian.

An apparent distinction between the stimuli of Tabossi and Laghi's (1992) Experiment 3 and those of the present experiment is that their nonwords were not derived from words but constructed so as to conform to the orthographic and phonotactic principles of Italian. Tabossi and Laghi imply that pseudowords derived from words are likely to be processed as modified lexical items, that is, to encourage dependency on the lexical route. The procedure adopted here of changing a letter in a word to derive a pseudoword was used by Sebastián-Gallés (1991), by Tabossi and Laghi (1992) in their Experiment 4, and by Baluch and Besner (1991). Evidence for lexical effects was found by Sebastián-Gallés and by Tabossi and Laghi but not by Baluch and Besner. Frost et al. (1987) used constructed pseudowords as in Tabossi and Laghi's (1992) Experiment 3 and found one lexical effect, that of frequency, but failed to find the other lexical effect, that of context. It seems unlikely, therefore, that a coherent understanding of the positive and negative findings in the literature can be established on the basis of differences in choices of pseudowords. Nevertheless, Tabossi and Laghi's concern for the influence on word priming of the nonword stimuli needs to be taken seriously; Smith, Theodor, and Franklin (1983)
Table 1

Mean Naming Latencies ( $M$, in Milliseconds) and Error Rates (in \%) With the Corresponding Standard Deviations $(S D$, in Milliseconds) for Subjects and Items When Pseudowords Were Present (Experiment 1)

\begin{tabular}{|c|c|c|c|c|}
\hline \multirow[b]{3}{*}{ Frequency } & \multicolumn{4}{|c|}{ Context } \\
\hline & \multicolumn{2}{|c|}{ Associated } & \multicolumn{2}{|c|}{ Nonassociated } \\
\hline & Latency & Error Rate & Latency & Error Rate \\
\hline \multicolumn{5}{|c|}{ Intact } \\
\hline \multicolumn{5}{|l|}{ High } \\
\hline$M$ & 507 & 1.39 & 518 & 0.83 \\
\hline$S D$ by subject & 54 & 3.51 & 57 & 2.80 \\
\hline$S D$ by item & 37 & 3.72 & 40 & 2.96 \\
\hline \multicolumn{5}{|l|}{ Low } \\
\hline$M$ & 516 & 0.28 & 528 & 0.56 \\
\hline$S D$ by subject & 53 & 1.67 & 57 & 2.32 \\
\hline$S D$ by item & 46 & 1.76 & 47 & 2.45 \\
\hline \multicolumn{5}{|c|}{ Degraded } \\
\hline \multicolumn{5}{|l|}{ High } \\
\hline$M$ & 535 & 1.39 & 548 & 0.00 \\
\hline$S D$ by subject & 58 & 3.51 & 56 & 0.00 \\
\hline$S D$ by item & 37 & 4.49 & 43 & 0.00 \\
\hline \multicolumn{5}{|l|}{ Low } \\
\hline$M$ & 548 & 0.83 & 553 & 0.83 \\
\hline$S D$ by subject & 52 & 3.68 & 57 & 2.80 \\
\hline$S \dot{D}$ by item & 51 & 2.96 & 50 & 2.96 \\
\hline
\end{tabular}

found related versus unrelated prime differences in lexical decision of 104, 54, and $-3 \mathrm{msec}$ for pseudowords one letter removed from words, random letter strings, and rows of Xs, respectively.

Conflicting results on the priming effect could arise from differences in the subject's task with respect to the primes. Frost et al. (1987) had subjects perform a lexical decision on the prime. Sebastián-Gallés (1991) had them read the prime silently, as in the present experiment. Neither Baluch and Besner (1991) nor Tabossi and Laghi (1992) provide any details about how the subjects were required to respond to the prime. The significance of the subject's task with respect to the prime cannot be underestimated. The magnitude of the difference between related and unrelated primes has been shown to be a function of the kind of processing conducted on the prime. In lexical decision and naming, a required semantic evaluation can lead to superior priming relative to simply reading the prime, which in turn can lead to superior priming relative to phonemic analysis; and when responses to the primes are only visual (e.g., searching for letters), priming can be nullified (e.g., Henik, Friedrich, \& Kellogg, 1983; Parkin, 1984; Smith et al., 1983). Clearly, variations in priming can be expected from variations in the subject's responsibility with respect to the prime, and when that responsibility is neither made explicit nor monitored by the experimenter, ambiguities about the basis of successful and unsuccessful priming can arise which may have little to do with the mechanisms that map print to pronunciation.

Such ambiguities can also arise from variations in the strength of the relatedness (association) between prime and target, a source of variation that is likely to figure 
prominently in cross-language studies where norms differ and methods of selecting materials cannot abide by common criteria. Strength of association is known to affect the priming of naming (see review by Neely, 1991) and the primed identification of masked words (Burt, Walker, Humphreys, \& Tehan, 1993). Similarly, the proportion of related stimulus pairs in an experiment affects degree of priming (e.g., de Groot, 1984; Keefe \& Neely, 1990) and appears to do so in a manner that is tied complicatedly to the onset asynchrony between prime and target (e.g., den Heyer, Briand, \& Dannenbring, 1983). Potential magnifiers of these effects of variations in associative strength and relatedness proportion are variations in the frequency of the targets (e.g., Becker, 1979) and the relative slowness of the subjects in responding (e.g., Hines, Czerwinski, Sawyer, \& Dwyer, 1986), both of which are known to affect priming. The moral, as above, is that differences in priming effects across experiments in different orthographies could have little to do with whether this or that experiment included or excluded pseudowords. To the extent that the full complement of sources of variation in priming is not recognized explicitly in an experiment, inferences from the outcome of the experiment to the primacy of this or that lexical access code can be drawn only tentatively.

Word frequency. Familiarity $(\mathrm{HF}=527 \mathrm{msec}$ vs. $L F=536 \mathrm{msec}$ ) was significant by subjects only $[F 1(1,35)=10.00, p<.003 ; F 2(1,78)=2.23, p>.05]$. Although the effect of frequency did not meet the stringent requirements of significance by both subjects and items, correlations between the naming latencies for individual target words and their familiarity ratings in the four subconditions provided strong confirmation of the effect's presence [for intact words in an associated context, $r=.32, F(1,78)=8.90, p<.004$; for intact words in an unrelated context, $r=.32, F(1,78)=9.07, p<.003$; for degraded words in an associated context, $r=.37$, $F(1,78)=12.48, p<.001$; and for degraded words in an unrelated context, $r=.32, F(1,78)=4.61, p<.03$ ]. In sum, the present results confirm the observations of Frost et al. (1987) and Lukatela and Turvey (1990b) on Serbo-Croatian in demonstrating frequency effects in the presence of pseudowords. The continuation of a wordfrequency influence when pseudowords must be named characterizes results in other shallow orthographies, namely, Spanish (Sebastián-Gallés, 1991) and Japanese Kana (Besner \& Hildebrandt, 1987).

There was no association $\times$ frequency interaction (both $F \mathrm{~s}<1$ ). An additivity of associative priming and word frequency in naming when both main effects are present is predicted by Besner and Smith (1992b) in contrast to an expected interaction of these variables in lexical decision. In their account, a two-way interaction is assumed between an orthographic input lexicon accessed directly by a letter string and the semantic system accessed by active representations in the orthographic lexicon. The orthographic input lexicon and the semantic system have one-way connections to the phonological output lexicon where names are found. The prime will activate a representation in the semantic system and, by spreading activation, the prime's associates. These will then activate related representations in the orthographic lexicon; hence, a priming effect. The target will activate its representation in the orthographic lexicon, which in turn will activate a representation in the phonological output lexicon, both directly and via the semantic system. Both pathways are frequency sensitive. If, for some reason (and here Besner and Smith offer no specifics), the semantic access of the phonological output lexicon is disabled or slowed, the name in the phonological output lexicon will be selected primarily by the pathway from the orthographic lexicon. Thus, the influence of context on naming arises in the orthographic lexicon and the influence of frequency arises independently in the pathway connecting the orthographic and phonological lexicons; hence, an additive effect of context and frequency.

Stimulus quality. The effect of stimulus quality was significant $[$ intact $=518 \mathrm{msec}$ vs. degraded $=547 \mathrm{msec}$; $F 1(1,35)=74.43, p<.001, F 2(1,78)=52.88, p<.001]$, but there was no stimulus quality $x$ association interaction (both $F_{\mathrm{S}}<1$ ). If anything, the trend was in the opposite direction: context effect for intact $=11 \mathrm{msec}$, context effect for degraded $=8 \mathrm{msec}$. Borowsky and Besner (1991) hypothesized that the failure of Lukatela and Turvey (1987) to find the interaction in Serbo-Croatian was because of an inappropriate baseline (asterisks). Clearly, that hypothesis is not supported by the present data.

Additionally, there was no stimulus quality $\times$ frequency interaction (both $F_{\mathbf{S}}<1$ ). The present results are in agreement with Besner and Smith's (1992b) prediction, but in the absence of the most important stimulus quality $x$ association interaction, it cannot be taken as support for their model of visual word recognition. In their view, degradation affects only the orthographic input lexicon which is also affected by the semantic system, whereas word frequency affects the connecting pathways between lexicons. Hence, the retrieval of a name by the pathway from the orthographic lexicon should result in an interaction of stimulus quality with association and an addition of stimulus quality and frequency.

\section{EXPERIMENT 2}

There are several reasons for conducting a second experiment in which naming is restricted to words. To begin with, there is the observation by Keefe and Neely (1990) that priming effects in English do not distinguish in magnitude as a function of the presence or absence of pseudowords. It would be useful, therefore, to see whether the same is true of Serbo-Croatian, given the expectations one might have by virtue of the shallow versus deep contrasts that can be drawn between its orthography and that of English. Because of the singleroute account favored for Serbo-Croatian, no difference in priming is expected from merely adding or subtracting pseudowords from the to-be-named stimuli. Second, there is a similar issue with respect to frequency: Will its 
effect be magnified when pseudowords are excluded? On the classical dual-route account, a word's frequency is more likely to be influential when access is more likely to be lexical than nonlexical. Accordingly, the biasing toward the lexical route presumed to follow from the exclusion of pseudowords should result in a magnification of the effect of frequency. In contrast, by the single-route account, no augmentation in the influence of frequency is expected from merely deleting pseudowords. Third, there remains the question of whether the stimulus quality $X$ association interaction repeatedly found in English is truly elusive in Serbo-Croatian. The marked failure to find this interaction in Experiment 1 warrants a further examination. Against the backdrop of classical dual-route theory, Lukatela and Turvey (1987) hypothesized that the stimulus quality $\times$ association interaction might depend on whether or not access was by the lexical route. By this thinking, if the exclusion of pseudowords encourages greater reliance on the lexical route, then the interaction should be more likely to occur. The fourth and final reason for replicating Experiment 1 with the exclusion of pseudowords is the theoretical importance of the other stimulus-quality interaction - that with frequency. As noted, one current interpretation of visual word recognition makes the novel prediction of an additive relationship of stimulus quality with frequency and an overadditive relationship of stimulus quality with association (Besner \& Smith, 1992b; Borowksy \& Besner, 1993). These contrasting expectations for stimulus quality deserve a further evaluation.

\section{Method}

Subjects. Forty-five high school seniors from the Fifth Belgrade Gymnasium served as subjects. Each subject was assigned to one of four groups, according to when the subject appeared at the laboratory. This resulted in 12 subjects in the first group and 11 subjects in each of the other three groups. None had participated in Experiment 1.

Materials. All word-word pairs from Experiment 1 were used again. Word-pseudoword pairs were omitted. There were, therefore, only half as many trials in Experiment 2.

Design and Procedure. The design and procedure were identical to those of Experiment 1.

\section{Results and Discussion}

Minimum and maximum acceptable latencies were set at \pm 2 standard deviations. Table 2 shows mean wordnaming latencies, mean errors, and standard deviations for the eight types of word-word pairs. A 2 (associative context) $\times 2$ (stimulus quality) $\times 2$ (familiarity) ANOVA on word-naming latencies and word-naming errors was conducted with subjects $(F 1)$ and items $(F 2)$ as error terms. The error analyses yielded no significant effects.

Associative priming. The ANOVA on latency revealed a significant main effect of associative priming [associated $=533 \mathrm{msec}$ vs. unassociated $=545 \mathrm{msec}$; $F 1(1,44)=22.08, p<.001, F 2(1,78)=7.57, p<.01]$. This effect, in the absence of pseudowords, is of the same magnitude as that observed in Experiment 1 in the presence of pseudowords (12 msec vs. $11 \mathrm{msec}$ and compa- rable $F 1$ and $F 2$ values). The fact that the priming effect in Serbo-Croatian seems to be indifferent to the presence or absence of pseudowords concurs with the observation in English by Keefe and Neely (1990) and contradicts expectations from classical dual-route arguments. The size of the relatedness effect in these two experiments (11 msec in Experiment 1 and $12 \mathrm{msec}$ in Experiment 2) is at the low end of what has been found for phonologically unambiguous Serbo-Croatian (Carello et al., 1988; Lukatela, Feldman, et al., 1989; Lukatela, Turvey, et al., 1989), but lexical effects on naming can be quite small, even for English (e.g., significant effects from 7 to $11 \mathrm{msec}$ were reported by Seidenberg et al., 1984).

Word frequency. As in Experiment 1, there was no association $\times$ frequency interaction $(F \mathrm{~s}<1)$; unlike in Experiment 1 , the main effect of familiarity or frequency $(\mathrm{HF}=$ $537 \mathrm{msec}$ vs. $\mathrm{LF}=541 \mathrm{msec}$ ) was not significant by either subjects or stimuli $[F 1(1,44)=2.61, p<.15 ; F 2<1]$. Once again, however, correlations pointed to a definite influence of a word's familiarity on the speed of its pronunciation [for intact words in an associated context, $r=.29$, $F(1,78)=7.16, p<.009$; for degraded words in an associated context, $r=.33, F(1,78)=9.53, p<.003$; and for degraded words in an unrelated context, $r=.24$, $F(1,78)=4.64, p<.03]$. The correlation for intact words in an unrelated context did not reach significance $[r=.15$, $F(1,78)=1.88, p>.05]$. Contrary to the hypothesis that excluding pseudowords enhances lexical effects, the present experiment has revealed a weaker effect of frequency, at worst, and an equal effect of frequency, at best, in relation to the effect observed in Experiment 1, in which pseudowords were named along with words.

Stimulus quality. The effect of stimulus quality was significant $[$ intact $=523 \mathrm{msec}$ vs . degraded $=555 \mathrm{msec}$;

Table 2

Mean Naming Latencies ( $M$, in Milliseconds) and Error Rates (in \%) With the Corresponding Standard Deviations ( $S D$, in Milliseconds) for Subjects and Items When Pseudowords Were Absent (Experiment 2)

\begin{tabular}{|c|c|c|c|c|}
\hline \multirow[b]{3}{*}{ Frequency } & \multicolumn{4}{|c|}{ Context } \\
\hline & \multicolumn{2}{|c|}{ Associated } & \multicolumn{2}{|c|}{ Nonassociated } \\
\hline & Latency & Error Rate & Latency & Error Rate \\
\hline \multicolumn{5}{|c|}{ Intact } \\
\hline \multicolumn{5}{|l|}{ High } \\
\hline$M$ & 517 & 0.89 & 528 & 1.56 \\
\hline$S D$ by subject & 61 & 2.88 & 71 & 3.67 \\
\hline$S D$ by item & 35 & 3.40 & 34 & 4.38 \\
\hline \multicolumn{5}{|l|}{ Low } \\
\hline$M$ & 524 & 0.44 & 525 & 0.67 \\
\hline$S D$ by subject & 72 & 2.08 & 70 & 2.52 \\
\hline$S D$ by item & 42 & 1.92 & 42 & 2.36 \\
\hline \multicolumn{5}{|c|}{ Degraded } \\
\hline \multicolumn{5}{|l|}{ High } \\
\hline$M$ & 538 & 1.11 & 563 & 0.67 \\
\hline$S D$ by subject & 69 & 3.18 & 78 & 2.52 \\
\hline$S D$ by item & 36 & 3.04 & 46 & 2.36 \\
\hline \multicolumn{5}{|l|}{ Low } \\
\hline$M$ & 553 & 1.11 & 565 & 1.33 \\
\hline$S D$ by subject & 69 & 3.18 & 79 & 3.44 \\
\hline$S D$ by item & 47 & 4.69 & 41 & 3.68 \\
\hline
\end{tabular}


$F 1(1,44)=80.21, p<.001, F 2(1,78)=54.47, p<.001]$. Importantly, there was no stimulus quality $\times$ frequency interaction (both $F_{\mathbf{S}}<1$ ), in agreement with Besner and Smith's (1992b) prediction. As in Experiment 1, the value of the latter result as support for their model of visual word recognition depends on the status of the stimulus quality $X$ association interaction. This interaction - which was insignificant by both analyses in Experiment 1 -reached significance by subjects in the present experiment $[F 1(1,44)=6.97, p<.01 ; F 2(1,78)=$ $1.67, p>.15]$. As a way of revealing the interaction, Borowsky and Besner (1991) suggest a procedure of eliminating those prime-target pairs that failed to show an associative effect. This procedure was applied to the present data to see if the interaction would emerge more fully when stimuli were trimmed. Again, significance was attained only by subjects $[F 1(1,44)=4.87, p<.05$; $F 2(1,48)=2.13, p>.15]$. In the ANOVA on errors, $F \mathrm{~s} \leq 1$. It seems, therefore, that the stimulus quality $X$ association interaction found repeatedly in English is less readily observed in Serbo-Croatian. And this intransigence is not attributable to the size of the associative effect; with English materials, Besner and Smith (1992b) found a relatedness effect of only $9 \mathrm{msec}$ for intact stimuli that ballooned to $99 \mathrm{msec}$ under degradation.

A counterpart English-language experiment. The ambiguity of the stimulus quality $X$ association interaction in the present Serbo-Croatian experiment, in combination with the overall closeness of the results to the expectations of Besner and Smith (1992b), motivated an English-language counterpart of Experiment 2. The experiment was conducted with 37 undergraduates from the University of Connecticut using the same computerized presentation and stimulus parameters as those used in the present Serbo-Croatian experiment. In the ANOVA on latencies, association (523 vs. $559 \mathrm{msec})$ was significant by both analyses $[F 1(1,36)=53.19, p<$ $.001 ; F 2(1,78)=39.46, p<.001]$, as was degradation $(514$ vs. $567 \mathrm{msec})[F 1(1,36)=230.74, p<.0001$; $F 2(1,78)=54.11, p<.001]$, but frequency (536 vs. $545 \mathrm{msec})$ was significant only by subjects $[F 1(1,36)=$ $6.64, p<.01 ; F 2(1,78)=1.43, p>.05]$. Most importantly, the stimulus quality $x$ association interaction was found to be significant $[F 1(1,36)=12.87, p<.001$; $F 2(1,78)=4.00, p<.05]$ - with the associative effect being $21 \mathrm{msec}$ for intact stimuli and $34 \mathrm{msec}$ for degraded stimuli-and the stimulus quality $\times$ frequency interaction was found to be insignificant (both $F \mathrm{~s}<1$ ). In the ANOVA on errors, association was significant by both analyses $[F 1(1,36)=9.55, p<.01 ; F 2(1,78)=$ $12.34, p<.001]$, as was degradation $[F 1(1,36)=5.42$, $p<.05 ; F 2(1,78)=7.81, p<.01]$, but frequency was significant by neither $(F \mathrm{~s}<1)$. As in the latency ANOVA, the stimulus quality $\times$ association interaction in the error data was significant $[F 1(1,36)=5.42, p<$ $.05 ; F 2(1,78)=10.15, p<.01]$ and the stimulus quality $\times$ frequency interaction was insignificant (both $F \mathrm{~s}<1$ ). It may be concluded, therefore, that (a) the stimulus quality $X$ association interaction that was insignificant in both the latency and error ANOVAs of Experiment 2 was pronounced in both ANOVAs in this Englishlanguage counterpart, and (b) the overall pattern of stimulus quality's interactions in this English-language experiment concurs with Besner and Smith's (1992b) expectations (Borowsky \& Besner, 1993).

\section{GENERAL DISCUSSION}

The primary purpose of the present research was to evaluate the hypothesis that lexical effects (associative priming, frequency) on naming words in a shallow orthography are eliminated when pseudowords must also be named. This hypothesis, derived from the classical dual-route theory, was contradicted by the data of Experiment 1 . A weaker hypothesis-that the exclusion of pseudowords enhances lexical effects relative to their inclusion-was also contradicted. Associative priming and the influence of frequency in Experiments 1 and 2 were not different in magnitude despite the difference between the experiments with regard to the presence of pseudowords. The importance of these results is in respect to the claim that the presence or absence of lexical effects on naming can be taken as evidence for the absence or presence, respectively, of assembled as opposed to accessed phonology. To reiterate, the additional experimental requirement of naming pseudowords is expected to bias the reader, particularly of a shallow orthography, to assembling rather than assessing word names. By classical dual-route theory, assembling entails neither of the lexical effects of associative priming and frequency. The observation of both effects in Experiment 1 renders false the argument that pseudowords engender a naming strategy that is indifferent to lexical knowledge.

Adding to this rejection of the classical dual-route interpretation of pseudoword influences is the important understanding that the effects of phonological ambiguity (e.g., Feldman \& Turvey, 1983; Lukatela, Feldman, et al., 1989), phonological priming (Lukatela et al., 1990; Lukatela \& Turvey, 1990b), alphabet priming (Lukatela, Turvey, et al., 1989; Lukatela et al., 1991), masked forward priming (Lukatela \& Turvey, 1990b), and backward phonological masking (Lukatela \& Turvey, 1990a) suggest that there is no visual lexical access in SerboCroatian word recognition over and above phonological access. Accordingly, the weight of the evidence from Serbo-Croatian studies leads one to conclude that the subjects in Experiment 1 named via the nonlexical route, that is, by assembled phonology. Despite this, lexical effects were significant under both subjects and items analyses. In sum, that lexical effects were found in Experiment 1 in the presence of pseudowords, and that the subjects in Experiment 1 probably named by the phonological route, means that observed lexical effects cannot point unequivocally to visual access and cannot be interpreted as contravening (prelexical) assembled phonology (Carello, Lukatela, \& Turvey, 1994; Seidenberg, 1992). As suggested in the Results and Discussion sec- 
tion of Experiment 1, the uneven pattern of results concerning lexical effects in different orthographies needs addressing in terms of variations in the multiple conditions that foster or discourage such effects. This is not meant as an indictment of the designs of previous studies, but rather as motivation to mine them for the source of differences in superficially similar experiments. To focus simply on the presence or absence of pseudowords will not suffice.

A subsidiary aspect of the present research was the evaluation of two interactions involving stimulus quality, one with association and one with frequency. The more heralded one is that between stimulus quality and association. Although found regularly in English, with relatively few exceptions, this interaction was not found in Serbo-Croatian by Lukatela and Turvey (1987). The failure may well have been due to the use of a baseline stimulus that did not invoke linguistic processing; the few reported failures to produce the interaction in English follow from similar conditions (e.g., Borowsky \& Besner, 1991; den Hyer \& Benson, 1988). Experiments 1 and 2, however, do not provide much support for the idea that additivity, as opposed to nonadditivity, of quality and association in Serbo-Croatian is a matter of choice of baseline. Both experiments used nonassociated words as the baseline stimuli and neither found statistical support for an interaction. Clearly, there is more to the stimulus quality $X$ association interaction than is covered by current theories, and resolution of the conflicting results will have to await further experiments. One obvious line of needed research is the parametric manipulation of the prominent quantities, namely, prime-target SOA and magnitude of the degradation effect. The region of the parameter space in which the interaction resides need not be identical across different orthographies.

One theory that seeks to address the stimulus quality $X$ association interaction is that of Besner and Smith (1992b). What is important about this theory is that it addresses both of the interactions between stimulus quality and the lexicon-the stimulus quality $X$ association interaction and the stimulus quality $x$ frequency interaction-and it does so via contrasting predictions. Experiments 1 and 2 with Serbo-Croatian found the expected noninteraction between quality and frequency but not, as noted, the expected interaction between quality and association. However, our subsidiary experiment with English, conducted as a cross-language replication of Experiment 2, yielded results consistent with both predictions of Besner and Smith's (1992b) model (see also Borowsky \& Besner, 1993). The least tendentious inference to be drawn from this positive outcome is that degradation and associative priming share a common process, whereas degradation and frequency do not. If it turns out to be the case that visual lexical access is initially, and possibly only, phonological, regardless of the orthography (Lukatela \& Turvey, 1994a, 1994b), the challenge will be that of understanding how the factorization of word frequency and active associative knowl- edge is manifest in the processes subsequent to prelexically assembled phonology.

\section{REFERENCES}

BALUCH, B., \& BESNER, D. (1991). Visual word recognition: Evidence for strategic control of lexical and nonlexical routines in oral reading. Journal of Experimental Psychology: Learning, Memory, \& Cognition, 17, 644-652.

BECKER, C. A. (1979). Semantic context and word frequency effects in visual word recognition. Journal of Experimental Psychology: Human Perception \& Performance, 5, 252-259.

Besner, D., \& Hildebrandt, N. (1987). Orthographic and phonologic codes in the oral reading of Japanese Kana. Journal of Experimental Psychology: Learning, Memory, \& Cognition, 13, 335-343.

BESNER, D., \& SMITH, M. C. (1992a). Basic processes in reading: Is the orthographic depth hypothesis sinking? In R. Frost \& L. Katz (Eds.), Orthography, phonology, morphology, and meaning (pp. 45-66). Amsterdam: Elsevier.

BesNer, D., \& SmITH, M. C. (1992b). Models of visual word recognition: When obscuring the stimulus yields a clearer view. Journal of Experimental Psychology: Learning, Memory, \& Cognition, 18, 468-482.

BorowsKy, R., \& BeSNER, D. (1991). Visual word recognition across orthographies: On the interaction between context and degradation. Journal of Experimental Psychology: Learning, Memory, \& Cognition, 17, 272-276.

BOROWSKY, R., \& BESNER, D. (1993). Visual word recognition: A multistage activation model. Journal of Experimental Psychology: Learning, Memory, \& Cognition, 19, 813-840.

Burt, J. S., Walker, M. B., Humphreys, M. S., \& Tehan, G. (1993). Associative priming in perceptual identification: Effects of primeprocessing requirements. Memory \& Cognition, 21, 125-137.

Carello, C., Lukatela, G., \& Turvey, M. T. (1988). Rapid naming is affected by association but not by syntax. Memory \& Cognition, 16, 187-195.

Carello, C., Lukatela, G., \& Turvey, M. T. (1994). Lexical involvement in naming does not contravene prelexical phonology: Comment on Sebastián-Gallés (1991). Journal of Experimental Psychology: Human Perception \& Performance, 20, 192-198.

Carello, C., Turvey, M. T., \& Lukatela, G. L. (1992). Can theories of word recognition remain stubbornly nonphonological? In R. Frost \& L. Katz (Eds.), Orthography, phonology, morphology, and meaning (pp. 211-226). Amsterdam: Elsevier.

COltheart, M. (1978). Lexical access in simple reading task. In G. Underwood (Ed.), Strategies of information processing (pp. 151216). London: Academic Press.

DE Groot, A. M. B. (1984). Primed lexical decision: Combined effects of the proportion of related prime-target pairs and the stimulusonset asynchrony of prime and target. Quarterly Journal of Experimental Psychology, 36A, 253-280.

DEN Heyer, K., \& Benson, K. (1988). Constraints on the additive relationship between semantic priming and word repetition and on the interactive relationship between semantic priming and stimulus clarity. Canadian Journal of Psychology, 42, 399-413.

den Heyer, K., Briand, K., \& Dannenbring, G. L. (1983). Strategic factors in the lexical decision task: Evidence for automatic and attention-driven processes. Memory \& Cognition, 11, 374-381.

Feldman, L. B., \& TURVEY, M.T. (1980). Words written in kana are named faster than the same words written in kanji. Language \& Speech, 23, 141-147.

Feldman, L. B., \& Turvey, M. T. (1983). Word recognition in SerboCroatian is phonologically analytic. Journal of Experimental Psychology: Human Perception \& Performance, 9, 288-298.

FoRSTER, K. I., \& CHAMBERS, S. M. (1973). Lexical access and naming time. Journal of Verbal Learning \& Verbal Behavior, 12, 627-635.

Frederiksen, J. R., \& Kroll, J. F. (1976). Spelling and sound: Approaches to the internal lexicon. Journal of Experimental Psychology: Human Perception \& Performance, 2, 361-379.

Frost, R. (1994). Prelexical and postlexical strategies in reading: Ev- 
idence from a deep and a shallow orthography. Journal of Experimental Psychology: Learning, Memory, \& Cognition, 20, 1-14.

Frost, R. (in press). Phonological computation and missing vowels: Mapping lexical involvement in reading. Journal of Experimental Psychology: Learning, Memory, \& Cognition.

Frost, R., Katz, L., \& BenTin, S. (1987). Strategies for visual word recognition and orthographical depth: A multilingual comparison. Journal of Experimental Psychology: Human Perception \& Perfor mance, 13, 104-115.

Grossberg, S., \& Stone, G. O. (1986). Neural dynamics of word recognition and recall: Priming, learning, and resonance. Psychological Review, 93, 46-74.

HeniK, A., Friedrich, F. J., \& Kellogg, W. A. (1983). The dependence of semantic relatedness effects upon prime processing. Memory \& Cognition, 11, 366-373.

Hines, D., CZerwinski, M., SAWyer, P. K., \& DWyer, M. (1986). Automatic semantic priming: Effect of category exemplar level and word association level. Journal of Experimental Psychology: Human Perception \& Performance, 12, 370-379.

Hudson, P. T. W., \& Bergman, M. W. (1985). Lexical knowledge in word recognition: Word length and word frequency in naming and lexical decision tasks. Journal of Memory \& Language, 24, 46-58.

Katz, L., \& Feldman, L. (1983). Relation between pronunciation and recognition of printed words in deep and shallow orthographies. Journal of Experimental Psychology: Learning, Memory, \& Cognition, 9, 157-166.

KeEFE, D. E., \& NeELY, J. H. (1990). Semantic priming in the pronunciation task: The role of the prospective prime-generated expectancies. Memory \& Cognition, 18, 289-298.

Lukatela, G., Carello, C., \& Turvey, M. T. (1990). Phonemic priming of words and pseudowords. European Journal of Cognitive Psychology, 2, 375-394.

Lukatela, G., Feldman, L. B., Turvey, M. T., Carello, C., \& Katz, L. (1989). Context effects in bi-alphabetical word perception. Journal of Memory \& Language, 28, 214-236.

LuKaTEla, G., \& TURVEY, M. T. (1987). Loci of phonological effects in the lexical access of words written in a shallow orthography. $P$ sychological Research, 49, 139-146.

Lukatela, G., \& Turvey, M. T. (1990a). Automatic and prelexical computation of phonology in visual word identification. European Journal of Cognitive Psychology, 2, 325-343.

Lukatela, G., \& Turvey, M. T. (1990b). Phonemic similarity effects and prelexical phonology. Memory \& Cognition, 18, 128-152.

Lukatela, G., \& Turvey, M. T. (1991). Phonological access of the lexicon: Evidence from associative priming with pseudohomophones. Journal of Experimental Psychology: Human Perception \& Performance, 17, 951-966.

LuKaTELA, G., \& TURVEY, M. T. (1993). Similar attentional, frequency, and associative effects for pseudohomophones and words. Journal of Experimental Psychology: Human Perception \& Performance, 19, 166-178.

Lukatela, G., \& Turvey, M. T. (1994a). Visual lexical access is initially phonological: 1 . Evidence from associative priming by words, homophones, and pseudohomophones. Journal of Experimental Psychology: General, 123, 107-128.

Lukatela, G., \& Turvey, M. T. (1994b). Visual lexical access is initially phonological: 2 . Evidence from phonological priming by homophones and pseudohomophones. Journal of Experimental Psychology: General, 123, 331-335.

lukatela, G., Turvey, M. T., Feldman, L. B., Carello, C., \& KATZ, L. (1989). Alphabet priming in bi-alphabetical word perception. Journal of Memory \& Language, 28, 237-254.

Lukatela, G., Turvey, M. T., \& Todorović, D. (1991). Is alphabet biasing in bi-alphabetical word perception automatic and prelexical? Journal of Experimental Psychology: Learning, Memory, \& Cognition, 17, 653-663.

MCCANN, R. S., \& BESNER, D. (1987). Reading pseudohomophones: Implications for models of pronunciation assembly and the locus of word frequency effects in naming. Journal of Experimental Psychology: Human Perception \& Performance, 13, 13-24.
MCCanN, R. S., Besner, D., \& DavelaAr, E. (1988). Word recognition and identification: Do word frequency effects reflect lexical access? Journal of Experimental Psychology: Human Perception \& Performance, 14, 693-706.

Meyer, D. E., SchVaneVeldT, R. W., \& Ruddy, M. G. (1975). Loci of contextual effects on visual word-recognition. In P. M. A. Rabbitt \& S. Dornic (Eds.), Attention and performance V (pp. 98-118). London: Academic Press.

NeELY, J. (1991). Semantic priming effects in visual word recognition: A selective review of current findings and theories. In D. Besner \& G. Humphreys (Eds.), Basic processes in reading: Visual word recognition (pp. 264-336). Hillsdale, NJ: Erlbaum.

PaAp, K. R., Noel, R. W., \& Johansen, L. S. (1992). Dual-route models of print to sound: Red herrings and real horses. In R. Frost \& L. Katz (Eds.), Orthography, phonology, morphology, and meaning (pp. 293-318). Amsterdam: Elsevier.

Parkin, A. J. (1984). Levels of processing, context, and the facilitation of pronunciation. Acta Psychologica, 55, 19-29.

Scarborough, D., Cortese, C., \& Scarborough, H. (1977). Frequency and repetition effects in lexical memory. Journal of Experimental Psychology: Human Perception \& Performance, 3, 1-17.

SebastiáN-Gallés, N. (1991). Reading by analogy in a shallow orthography. Journal of Experimental Psychology: Human Perception \& Performance, 17, 471-477.

SEIDENBERG, M. S. (1992). Beyond orthographic depth in reading: Equitable division of labor. In R. Frost \& L. Katz (Eds.), Orthography, phonology, morphology, and meaning (pp. 85-118). Amsterdam: Elsevier.

Seidenberg, M. S., Waters, G. S., Sanders, M., \& Langer, P. (1984). Pre- and postlexical loci of contextual effects on word recognition. Memory \& Cognition, 12, 315-328.

Smith, M. C., Theodor, L., \& Franklin, P. E. (1983). The relationship between contextual facilitation and depth of processing. Journal of Experimental Psychology: Learning, Memory, \& Cognition, 9, 697-712.

TABOSSI, P., \& LaGHI, L. (1992). Semantic priming in the pronunciation of words in two writing systems: Italian and English. Memory \& Cognition, 20, 303-313.

TAFT, M., \& Russell, B. (1992). Pseudohomophone naming and the word frequency effect. Quarterly Journal of Experimental Psychology, 45A, 51-71.

\section{NOTES}

1. With respect to failures to show a semantic priming effect of naming in Serbo-Croatian (Frost et al., 1987, and Katz \& Feldman, 1983, who used the same stimulus set), Katz and his colleagues did not rule out lexical involvement, concluding only that "lexical mediation plays less of a role in naming Serbo-Croatian than in English" (Katz \& Feldman, 1983, p. 164) and "in Serbo-Croatian, as in other languages, lexical involvement in naming can be manipulated" (Frost et al., 1987, p. 110)

2. Some investigators report incorrectly that Frost et al. (1987) failed to find a frequency effect in naming Serbo-Croatian but did find such an effect in English (e.g., Besner \& Smith, 1992a; SebastiánGallés, 1991). We are uncertain as to how this error arose, given that Frost et al. state clearly on p. 107 that HF words were named faster than LF words $[F(1,69)=137.99]$, and that the interaction between word frequency and language (Serbo-Croatian, English, Hebrew) was insignificant $[F(2,69)=1.57]$. And on p. 108 , they say explicitly "word frequency did not have a significantly different effect on naming English and Serbo-Croatian words."

3. This fairly specialized mechanism seems to undermine the universality that Baluch and Besner claim for their model. A vowel check certainly would not generalize to other languages in which pseudowords have been found to matter (Dutch, Italian, Japanese, Spanish). Yet the effect of pseudowords in these other languages has been claimed as evidence for universality (Besner \& Smith, 1992a).

4. Although Baluch and Besner note correctly that transparent words use vowel letters to indicate vowel sounds, it is the case that 
these same letters are used to indicate consonants. Therefore, letter strings containing them are not completely unambiguous phonologically. This may be a source of inconsistency in the data and their interpretation (see Frost, 1994)

5. Other evidence from Japanese, however, shows that an expected familiarity advantage can be overwhelmed by a phonological transparency advantage. In a task in which subjects repeatedly named six Japanese color words, latencies were faster for kana phonographic transcriptions than for the visually more familiar kanji logographic versions (Feldman \& Turvey, 1980). That is to say, even though it is conventional to write color words in kanji, a significant advantage was found for the visually less familiar but sound-referencing kana forms.

(Manuscript received October 4, 1993; revision accepted for publication June 16,1994 .) 